\title{
CARACTERIZAÇÃO DOS ESTUDANTES DE ENSINO MÉDIO QUANTO À NÃO PARTICIPAÇÃO DAS AULAS DE EDUCAÇÃO FÍSICA ESCOLAR EM ESCOLAS DE UM MUNICÍPIO DE MÉDIO PORTE NO INTERIOR DO CEARÁ
}

\begin{tabular}{c}
\hline CHARACTERIZATION OF HIGH SCHOOL STUDENTS ABOUT THE NON- \\
PARTICIPATION OF SCHOOL PHYSICAL EDUCATION CLASSES IN SCHOOLS OF \\
THE MUNICIPALITY OF MEDIUM IN THE INTERIOR OF CEARÁ \\
\hline CARACTERIZACIÓN DE LOS ESTUDIANTES DE SECUNDARIA SOBRE LA NO \\
PARTICIPACIÓN DE LA EDUCACIÓN FISICA ESCOLAR LAS CLASES EN LAS \\
ESCUELAS DEL MUNICIPIO DE MEDIA EN EL INTERIOR DE CEARÁ
\end{tabular}

\author{
Francisco Carlos de Sousa Silval, \\ André Luis Façanha da Silva, ${ }^{2}$ \\ Alisson Slider do Nascimento Paula ${ }^{2}$
}

\begin{abstract}
RESUMO
O objetivo do estudo foi caracterizar o perfil dos alunos que não participam das aulas de educação física no ensino médio de escolas públicas da cidade de Sobral no Ceará. Para trato metodológico deste estudo foram coletados documentos de atestados e declarações entregues ao professor pelos alunos como pedido de dispensa das aulas com a realização de análises de dados construídos a partir dos resultados desses documentos. Percebeu-se que a maioria dos casos de alunos que não participam das aulas de educação física são representados por indivíduos do sexo feminino, motivos como cursos, estágio, trabalho, são os que contêm maior incidência, falta de acesso pela distância, práticas corporais realizadas fora da escola foram outros problemas detectados, o que implica que o maior causador do problema está no fato das aulas serem realizadas fora do turno normal dos demais componentes curriculares.
\end{abstract}

PALAVRAS-CHAVE: Ensino médio. Dispensa. Educação física escolar. Alunos. Aulas.

\begin{abstract}
The objective of this study was to characterize the profile of students who do not participate in the physical education classes in high school public schools of the city of Sobral in Ceará. To deal with this study were collected methodological documents of certificates and statements delivered to the teacher by the students as request for dispensation from classes with data analyses, constructed from the results of these documents. It was noticed that most cases of students who do not participate in the physical education classes are represented by females, reasons such as courses, internship, job, are those containing a higher incidence, lack of access by the distance, bodily practices held outside of school were other problems detected, implying that the greatest cause of the problem lies in the fact that the classes be held outside of the normal shift from other curricular components.
\end{abstract}

KEYWORDS: High school. The pantry. School physical education. Students. Class.

\section{RESUMEN}

\footnotetext{
${ }^{1}$ Universidade do Vale do Acaraú - UVA, Sobral, Ceará - Brasil

${ }^{2}$ Universidade Federal do - UFC, Fortaleza, Ceará - Brasil 
El objetivo de este estudio fue caracterizar el perfil de los estudiantes que no participan en las clases de educación física en las escuelas públicas de secundaria de la ciudad de Sobral, en Ceará. Para hacer frente a este estudio fueron recogidos los documentos metodológicos de certificados y declaraciones entregadas al profesor por los alumnos como petición para la dispensación de las clases con el análisis de datos, construido a partir de los resultados de estos documentos. Se observó que la mayoría de los casos de estudiantes que no participan en la educación física las clases están representadas por mujeres, razones tales como cursos, pasantías, trabajo, es aquellos que contienen una mayor incidencia, la falta de acceso por la distancia, las prácticas corporales celebrada fuera de la escuela fueron otros problemas detectados, lo que implica que la mayor causa del problema reside en el hecho de que las clases se celebrará fuera del paso normal de otros componentes curriculares.

PALABRAS CLAVE: High school secundaria. La despensa. Educación física escolar. Estudiantes. Clase. 


\section{INTRODUÇÃO}

O tema desta pesquisa emergiu a partir do componente curricular estágio supervisionado no ensino fundamental do curso de licenciatura em educação física. ${ }^{3} \mathrm{Na}$ ocasião, na escola selecionada para o desenvolvimento do estágio supervisionado foi identificado uma pasta de cor "vermelha", se tratava de várias declarações e atestados de alunos relacionados às dispensas das atividades da Educação Física Escolar.

A quantidade de pedidos de afastamento pelos estudantes do ensino médio da disciplina de Educação Física Escolar provocou uma inquietação que acarretou uma curiosidade em conhecer os motivos que levam os discentes do ensino médio se ausentar das aulas do componente curricular em tela. O conteúdo da pasta "vermelha" fomentou um interesse de perscrutar sobre este problema escolar. ${ }^{4}$

No que tange aos aspectos legais, os educandos podem solicitar afastamento das aulas de educação física escolar amparada pela Lei n 9.394, de 20 de dezembro de 1996, conforme a Lei de Diretrizes e Bases da Educação Nacional (LDB), uma vez que o aparato legislativo educacional compreenda que outras atividades podem ser consideradas como motivos relevantes para que o aluno possa não participar das aulas, possibilitando, deste modo, certa evasão da disciplina pelo fato não só da necessidade do aluno precisar fazer outra atividade fora da escola, como cursos ou estágio, mas também pelo provável desinteresse pela disciplina de Educação Física.

Outros motivos casuais também interferem nessa evasão, como atestados médicos e prole, causas que justificam a não participação do educando nas aulas, entretanto, existem algumas situações referentes a esses motivos que devem ser analisados de forma minuciosa, por exemplo, os atestados médicos podem representar diversas condições que devem ser muito bem assistidas pelos professores, primeiro deve-se olhar que motivo está descrito no atestado, caso seja algum acidente que tenha acontecido com o aluno que o possa ter deixado com sequelas e consequentemente ter ocasionado alguma deficiência, já entra o fator da inclusão, sendo assim, o aluno poderá sim participar das aulas dependendo de suas possibilidades e

\footnotetext{
${ }^{3}$ Universidade Estadual Vale do Acaraú, localizada no semiárido, na região norte do Estado do Ceará.

${ }^{4}$ Compreendemos como problema escolar em função da Educação Física escolar está inserida no currículo da educação nacional, possuindo mecanismos avaliativos que representam o desempenho no processo de escolarização dos educandos.
}

\begin{tabular}{|l|l|l|l|l|l|l}
\hline (C) Conexões & Campinas, SP & v. 14 & n. 1 & p. 35-52 & jan./mar. 2016 & ISSN 1983-9030
\end{tabular}


recuperação física, outra questão do atestado a ser analisada é em relação ao tempo, o aluno pode se machucar acidentalmente o que poderá causar abandono das aulas ainda que momentaneamente.

Com relação à prole, caso exclusivo das mulheres, consideramos plausível, quando as mulheres engravidam que tenham que abdicar de considerável parte da vida escolar para se dedicar ao período materno, o que a afastará por um vasto tempo da escola até que possa novamente aliar seu tempo tanto familiar quanto pessoal para poder dar continuidade aos estudos interrompidos.

Para que não se trate o tema como algo banalizado por parte dos alunos, é preciso citar a redação dada pela Lei $n^{\circ} 10.793$ de $1^{\circ}$ de dezembro de 2003, presente no artigo $3^{\circ}$ da LDB $^{1}$ que diz que:

A Educação Física, integrada à proposta pedagógica da escola, é componente curricular obrigatório da educação básica, sendo sua prática facultativa ao aluno: I que cumpra jornada de trabalho igual ou superior a seis horas; II - maior de trinta anos de idade; III- que estiver prestando serviço militar inicial ou que, em situação similar, estiver obrigado à prática da Educação Física; IV - amparado pelo DecretoLei $\mathrm{n}^{\circ} 1.044$, de 21 de outubro de 1969; V - (VETADO); VI - que tenha prole.

Sendo assim, o referido estudo busca contribuir qualitativamente para o debate acerca da evasão das aulas de educação física escolar, problema central em nossa pesquisa. Portanto, nos itens subsequentes pretendemos ir a fundo ao que toca os elementos subjacentes ocultos nesta questão educacional.

\section{O que apontam alguns estudos sobre a evasão das aulas de educação física}

Vejamos agora o que alguns estudos falam sobre essa questão da Evasão de alunos das aulas de educação física do ensino médio em conexão com os pedidos de dispensa dos alunos nas aulas de educação física. O estudo de Martins $^{2}$ aponta através de investigações sobre os discursos de legitimação em comparação com os documentos oficiais da escola como Projeto Político Pedagógico (PPP), que existe certa ambiguidade no que é legalizado e o que se entende sobre isso, na escola, por exemplo, o que legitima a disciplina de educação física são as aulas teóricas enquanto as práticas são consideradas facultativas por não serem inseridas no horário normal das demais disciplinas, compreendendo, assim uma dicotomia entre teoria e prática. 
Nesse sentido, para $\operatorname{Lemos}^{3}$ as reflexões acerca da realidade da educação física enquanto sua composição no currículo da escola, novamente aponta para os discursos que a legitimam como componente obrigatório e com relevância na grade curricular na escola para que a mesma não seja tratada ou vista como uma disciplina complementar na escola.

Os autores Veras e Cavalieri $\mathrm{Jr}^{4}{ }^{4}$ abordam a reflexão ao que contrapõe a educação física escolar e a Lei de Diretrizes e Bases (LDB), com objetivo de alertar aos pais e alunos a importância que a disciplina tem para o desenvolvimento psicológico e cognitivo dos alunos, no intuito de aumentar a participação dos mesmos nas aulas.

Ainda sobre as bases legais da educação física no ensino médio, o trabalho de Carneiro ${ }^{5}$ reflete a luz das duas versões da redação da LDB que versa sobre a educação física no ensino noturno, onde estabeleceu confrontos entre as duas, apresentou contribuições na interpretação da forma que a educação física ora facultativa e agora obrigatória no ensino noturno tem se apresentado no cenário escolar e aos olhos dos profissionais, a educação física no ensino noturno precisa ser revista com o intuito de oportunizar o ensino da disciplina para os alunos deste turno da mesma forma que acontece nos demais turnos. Argumenta que essa questão poderá vir a ser discutida no planejamento anual com os professores da escola em geral.

Sobre a dimensão da facultatividade nas aulas de educação física escolar para o ensino médio, o estudo de campo realizado na cidade de Hortolândia no estado de São Paulo, através de aplicação de questionários com alunos de escolas estaduais, verificou-se que deixar facultativa a participação dos estudantes nas aulas de educação física, possibilitada pela LDB é o fator principal que os levam a pedir afastamento das aulas. ${ }^{6}$

Este estudo se faz relevante para educação física no ensino médio, como uma maneira de tentar identificar os motivos que levam os alunos a não participarem das aulas de educação física escolar, quais as causas desses motivos? Como acontecem? Com base nisso tentar explanar possíveis soluções para enfrentar este problema, uma vez que se trata de um entrave concreto e requer ser tratado de modo meticuloso e que venha a contribuir, inclusive para professores ainda em seu processo de formação. 
Feita a reflexão a partir dos estudos, coube agora voltar os olhos para a questão problema: qual o perfil escolar e os motivos da evasão dos estudantes de escolas públicas do Ensino Médio na sede do município de Sobral/Ce?

\section{OBJETIVO}

O objetivo deste trabalho é caracterizar o perfil demográfico, escolar e os motivos que geram a evasão dos estudantes das aulas de educação física escolar de escolas públicas do ensino médio na sede do município de Sobral no estado do Ceará.

\section{METODOLOGIA}

Optamos por desenvolver uma pesquisa de campo no decorrer do ano de 2014 onde foi realizado um estudo do tipo exploratório e descritivo, no qual consistiu em uma busca em oito escolas estaduais de ensino médio num período de seis meses, junto com os professores das respectivas instituições. Foi realizada uma coleta de documentos referentes aos pedidos de dispensa dos alunos das aulas de educação física, em seguida construiu-se um banco de dados e de informações com esses documentos.

O local escolhido para ser realizada esta pesquisa foi o município de Sobral no Estado do Ceará, após uma busca no site da Secretaria de Educação do Estado (SEDUC), elencou-se algumas escolas, em seguida foi-se a campo para buscar os documentos que apontavam os motivos das evasões da Educação Física Escolar.

Os critérios utilizados para a amostra desta pesquisa foram feitas a partir da necessidade do estudo em acordo com as possibilidades encontradas como, por exemplo, os documentos emitidos pelos alunos para dispensa das aulas, a escola com maiores quantidade de estudante no ensino médio, adesão do professor e da direção da escola ao termo de anuência do fiel depositário e a garantia da confiabilidade e anonimato.

Alguns pontos dificultaram a pesquisa em função de algumas escolas não formularem critérios para que haja uma organização acerca dos pedidos de isenção das aulas de uma forma melhor elaborada para que se tenha um controle sobre esses alunos. Observamos casos 
de aluno onde não tinha um documento, onde a dispensa das aulas fora negociada informalmente através de diálogos com o professor e anotada no diário de classe.

Estudo com base em análise documental é feita através de documentos como material primordial, sejam revisões bibliográficas, prontuários, matriculas escolares, mapas de frequência escolar, cadastros entre outros documentos, extrai deles toda a análise, organizando-os e interpretando-os segundo os objetivos da investigação proposta. ${ }^{7}$

Para tabulação e analise dos documentos, construímos um banco de dados através do software Epi Info, ${ }^{8}$ que é usado pelo programa da Organização Mundial da Saúde (OMS) para coletar e analisar dados. Este software foi desenvolvido pelo Centro para Controle e Prevenção de Doenças (CDC), é gratuito e pode ser baixado pela Web.

Através do uso do Epi Info é possível trabalhar várias funções para obter resultados de forma quantitativa com maiores detalhes nos dados, através da inserção de dados previamente construídos por meio das coletas feitas e organizadas em um formulário ou questionário, esses dados são analisados para criação de mapas, relatórios, tabelas, dentre outras representações realizadas pelo software.

A criação dos formulários para serem inseridos e analisados pelo Epi Info foi construída a partir dos motivos alegados nos documentos referentes às declarações, e atestados dos alunos para pedirem dispensa das aulas de educação física escolar, com diversas variáveis encontradas nestes documentos como, por exemplo, idade, sexo, série, turno, data de emissão da declaração e os motivos como trabalho, prole, dentre outros, desses motivos eram ainda separadas outras categorias como tipo de trabalho, tipo de curso ou motivo do atestado médico. 


\section{DISCUSSÃO DOS RESULTADOS}

Realizada a coleta e análise, pode-se chegar a alguns números que explicam os principais motivos que contribuem para esse processo de evasão das aulas de educação física escolar. A seguir apresentam-se as Tabelas 1, 2 e 3 com o perfil demográfico e escolar dos estudantes conforme os atestados.

TABELA 1 - Perfil demográfico (sexo e idade) dos estudantes de ensino médio que não participam das aulas de educação física escolar de escolas públicas de Sobral, Ceará

\begin{tabular}{lrrrrr|r}
\hline \multicolumn{1}{c}{ IDADE } & \multicolumn{2}{c}{ Masculino } & \multicolumn{2}{c}{ Feminino } & \multicolumn{2}{c}{ TOTAL } \\
\cline { 2 - 8 } & $\mathbf{N}^{\mathbf{0}}$ & \multicolumn{1}{c}{$\%$} & \multicolumn{1}{c}{$\mathbf{N}^{\mathbf{0}}$} & \multicolumn{1}{c}{$\%$} & $\mathbf{N}^{\mathbf{0}}$ & \multicolumn{1}{c}{$\%$} \\
De 15 a 16 anos & 20 & 55,6 & 24 & 39,3 & 44 & 45,4 \\
De 17 a 18 anos & 13 & 36,1 & 34 & 55,7 & 47 & 48,5 \\
De 19 a 20 anos & 03 & 8,3 & 02 & 3,3 & 05 & 5,2 \\
Mais de 20 anos & 00 & 00 & 01 & 1,64 & 01 & 1,0 \\
TOTAL & $\mathbf{3 6}$ & $\mathbf{3 7 , 1}$ & $\mathbf{6 1}$ & $\mathbf{6 2 , 9}$ & $\mathbf{9 7}$ & $\mathbf{1 0 0}$ \\
\hline
\end{tabular}

Observamos pela Tabela 1 que os alunos do sexo feminino predominam a lista dos estudantes que são dispensados das aulas de educação física, percebe-se que a maioria dos alunos do sexo masculino está inserida na faixa etária que compreende dos 15 aos 16 anos e que dos 17 e 18 anos existe uma predominância das meninas. Na análise da Tabela 04 identificamos que os alunos estão distribuídos em maior escala nas séries avançadas como $2^{\circ}$ e $3^{\circ}$ anos do Ensino Médio.

TABELA 2 - Perfil demográfico e escolar (sexo e série) dos estudantes de ensino médio que não participam das aulas de educação física escolar de escolas públicas de Sobral, Ceará

\begin{tabular}{|c|c|c|c|c|c|c|}
\hline \multirow[t]{2}{*}{ SÉRIE } & \multicolumn{2}{|c|}{ Masculino } & \multicolumn{2}{|c|}{ Feminino } & \multicolumn{2}{|c|}{ TOTAL } \\
\hline & $\mathbf{N}^{\mathbf{0}}$ & $\%$ & $\mathbf{N}^{\mathbf{0}}$ & $\%$ & $\mathbf{N}^{0}$ & $\%$ \\
\hline $1^{\circ}$ Ano/série & 10 & 10,3 & 03 & 3,1 & 13 & 13,4 \\
\hline $2^{\circ}$ Ano/série & 18 & 18,6 & 33 & 34,0 & 51 & 52,6 \\
\hline $3^{\circ}$ Ano/série & 08 & 8,2 & 25 & 25,8 & 33 & 34,0 \\
\hline TOTAL & 36 & 37,1 & 61 & 62,9 & 97 & 100 \\
\hline
\end{tabular}


TABELA 3 - Distribuição dos estudantes sobre os motivos dos afastamentos das aulas de educação física escolar no ensino médio de escolas públicas de Sobral, Ceará

\begin{tabular}{|c|c|c|}
\hline MOTIVO & $\mathbf{N}^{\mathbf{0}}$ & $\%$ \\
\hline Curso & 28 & 28,9 \\
\hline Acesso/Distância & 18 & 18,6 \\
\hline Estágio & 16 & 16,5 \\
\hline Trabalho & 09 & 9,3 \\
\hline Atestado Médico & 09 & 9,3 \\
\hline Pessoal & 07 & 7,2 \\
\hline Prática Corporal Extraescolar & 05 & 5,2 \\
\hline Prole & 05 & 5,2 \\
\hline TOTAL & 97 & 100,0 \\
\hline
\end{tabular}

Levando em consideração as Tabelas 1, 2 e 3, onde se viu a predominância das mulheres e analisando a Tabela 3, relacionada aos motivos, observa-se que somando as categorias cursos, trabalho e estágio que se assemelham em termos de objetividade dos alunos, apresentam-se como os fatores predominantes encontrados nos atestados e declarações dos estudantes dispensados das aulas de educação física, compreende-se então que provavelmente a mulher tem maior preocupação em se inserir no mercado de trabalho.

Segundo dados do IBGE de $2012^{9}$ num período de oito anos que compreende entre 2003 a 2011, houve um crescimento significativo da presença de mulheres nos diversos setores do mercado de trabalho em relação aos homens, setores como comércio, prestação de serviços a empresas dentre outros setores com aumento de mais de 3 e 4 pontos percentuais.

Algumas outras hipóteses podem ser elencadas para explicar essa maioria feminina que não participa das aulas de educação física escolar. A "velha" dicotomia da separação de gêneros ocasionada pela exclusiva prática esportiva na escola que é taxada como atividade em que os estudantes do sexo masculino dominam por obter diferenças fisiológicas que os atribuem certa vantagem física, ou seja, os homens são tidos ou se acham mais fortes e habilidosos, portanto não podem jogar com as meninas.

Sobre essa questão, $\operatorname{Altman}^{10}$ fala que a seleção dos conteúdos e atividades por parte dos professores de educação física contribui para separação dos gêneros nas aulas, por exemplo, a utilização de apenas esportes onde os homens acabam por não querer jogar com as mulheres 
por entenderem que eles são mais ágeis, habilidosos e fortes, são um dos fatores, cabe ao professor planejar suas aulas no intuito de banir esse pensamento e acabar com essa separação, com a utilização de equipes mistas e outras metodologias e possíveis novas orientações pedagógicas em suas aulas.

Referente ao motivo CURSO no total temos 28 alunos representando $28,9 \%$ do total de alunos pesquisados sendo que 8 estão no curso de língua estrangeira representando 8,2\%, 3 no curso de música representando 3,1\%, 6 em cursos profissionalizantes representando 6,2\%, 10 em cursos de informática representando $10,3 \%$ e 1 não especificou o tipo de curso no atestado representando $1 \%$.

Dos alunos que estão em ESTÁGIO ao total encontramos 16 representando $16,5 \%$ dos alunos pesquisados, sendo que 7 estagiam no comércio representando 7,2\%, 5 estagiam em alguma empresa representando 5,2\%, 2 estagiam em algum programa do governo representando $2,1 \%$ e outros 2 representando $2,1 \%$ não especificaram o tipo de estágio.

Em relação aos alunos que estão na categoria TRABALHO temos 9 alunos representando 9,3\% dos alunos pesquisados, sendo que 1 trabalha no comércio representando $1 \%, 3$ trabalham na indústria representando $3,1 \%$, outros 3 trabalham em empresa representando $3,1 \%, 1$ trabalha em um setor do governo representando $1 \%$, e outro aluno não especificou o tipo de trabalho também representando $1 \%$.

A necessidade do aluno em se inserir cada vez mais cedo no mercado trabalho faz com que o mesmo assuma algumas responsabilidades enquanto estudante, que pode levá-lo a abandonar a escola para se dedicar apenas ao trabalho, com isso, é importante salientar que o aluno não pode perder o incentivo pelos estudos mesmo sabendo da sua realidade social e é dever da escola poder ajudar nesse processo através da conscientização e da criação de políticas públicas e programas em apoio com o governo.

Assim, observam-se algumas implicações no caráter que o ensino médio deve assumir como preparador para o mundo profissional, principalmente no que diz respeito à atual situação do país com o crescimento das escolas técnicas, que em termos estruturais contribuem para diminuir os índices de evasão no ensino médio, embora seja um problema ainda recorrente. ${ }^{11}$

\begin{tabular}{|l|l|l|l|l|l|l}
\hline CC Conexões & Campinas, SP & v. 14 & n. 1 & p. 35-52 & jan./mar. 2016 & ISSN 1983-9030
\end{tabular}


Em relação aos alunos que tem dificuldade em ter ACESSO à escola em outros horários pela questão da distância de suas residências foram encontrados 18 alunos representando 18,6\% do total de alunos pesquisados, sendo que 13 moram em distritos representando 13,4\%, 1 mora em região Periurbana representando 1\%, 2 moram na sede do município mas alegam não ter como chegar até a escola em outros horários representando $2,1 \%$ e outros 2 alunos moram em outro município também representando $2,1 \%$.

Um estudo realizado por Da Rosa ${ }^{12}$ com alunos de uma escola de ensino médio pública da cidade de Santa Maria no Rio Grande do Sul em 2010, percebeu-se pela fala dos alunos que pediam dispensa das aulas de educação física, que a falta de recursos para se locomover até a escola em horários restritos implicava na dificuldade do acesso destes às aulas de educação física.

A carência de oferta de transporte até a escola para os estudantes em outros horários dificulta não só a participação dos alunos nas aulas de educação física, mas também o acesso à escola para realizar outras atividades de necessidade dos alunos como pesquisas, participação de projetos, carga horária de estudos estendida entre outras.

Quanto aos motivos dos ATESTADOS MÉDICOS emitidos pelos alunos, foram encontrados 9 alunos representando 9,3\% do total de alunos pesquisados, sendo que 1 alega ter feito uma cirurgia, 1 ter alergia, 1 informa ter problemas gastrointestinais, 1 alega estar se recuperando de uma fratura, esses casos representando $1 \%$, outros 4 alunos não especificaram os motivos nos atestados representando $4,1 \%$.

O decreto $\mathrm{n}^{\mathrm{o}} 888^{13}$ de 04 de agosto de 1993 revogou o art. 12 do decreto de $\mathrm{n}^{\mathrm{o}} 69.450$ de 01 de novembro de 1971 que definiu a não obrigatoriedade de o aluno apresentar exame médico no início do ano letivo para participar das aulas de educação física, sendo assim, fica a cargo da escola solicitar ao aluno que assine um termo de responsabilidade para poder participar das aulas práticas, contudo, nestas escolas qualquer tipo de atestado é aceito para legitimar a dispensa dos alunos das aulas, sem ter uma perícia mais apurada e sem ter uma critica se de fato os motivos alegados nesses atestados são plausíveis para a efetivação desta dispensa. 
Problemas como luxação, dores crônicas e cirurgias são motivos que temporariamente limitam o aluno de realizar as práticas corporais, já outros motivos alegados nos atestados precisam ser bem analisados para saber se de fato é um motivo para que o aluno não participe das aulas de educação física.

Quanto à classificação do local e tipo de prática corporal extraescolar foram encontrados 5 casos de alunos representando 5,2\% do total de alunos pesquisados, todos esses alunos, alegam não poder participar das aulas de educação física escolar por estarem praticando exercício de força ou musculação em academias de ginástica.

É necessário caracterizar o tipo e o espaço onde os alunos realizam as práticas corporais pelo fato da contradição que cerca essa situação, é difícil entender que os alunos troquem a vivência da educação física na escola para realizá-las em outros locais como academias de ginástica, clubes, escolinhas de futebol, entre outros, engendra certa incoerência esta prática como motivo para o aluno pedir afastamento das aulas. Há uma flexibilidade acerca desta questão, o que se torna totalmente inadmissível, logo o que se percebe é que o aluno está dando pouca importância a prática corporal realizada na aula de educação física, deixando-a de lado para realizá-la em outro local, daí surge o questionamento direcionado a escola em relação a essa fiscalização da vida extraescolar do aluno no que diz respeito a esta prática que deveria ser realizada na escola.

A classificação de estudantes relacionados à PROLE foram encontrados 5 casos representando 5,2\% do total de alunos pesquisados, todos do gênero feminino. Quando se pensa na questão da prole logo vem à tona um assunto que requer uma devida atenção e que é muito discutido na escola que é a questão do sexo e gravidez na adolescência.

Várias estratégias são necessárias e devem ser colocadas pela escola para contribuir para a diminuição da gravidez precoce principalmente por parte das mulheres que são as mais prejudicadas nesses casos, diálogo com os pais que são os orientadores mais diretos por conta dos laços afetivos, campanhas de conscientização não só na escola como em outros locais em que o assunto possa ser explorado visando sempre evitar que os jovens interrompam o ciclo da vida estudantil para se dedicar integralmente a família, pulando uma etapa importante da vida.

\begin{tabular}{|l|l|l|l|l|l|l}
\hline CCConexões & Campinas, SP & v. 14 & n. 1 & p. 35-52 & jan./mar. 2016 & ISSN 1983-9030
\end{tabular}


Quando os alunos passam pela responsabilidade de assumir uma família tendo que conciliá-la com a escola, no caso das mulheres para ser mais exato, fica evidente a impossibilidade de frequentar as aulas de educação física por ser uma disciplina que exige da mulher uma prática corporal que não pode ser correspondida pelo seu estado físico, essa impossibilidade é estendida até depois que a criança nasce, onde a preocupação se direciona aos cuidados da mãe com sua prole, o que faz com que seu afastamento das aulas perdure até que a criança atinja especifica idade.

O trabalho de conscientização dos cuidados de prevenção da gravidez na adolescência passa por um trabalho em conjunto dos pais, bem como da escola, devido a representatividade que cada um possui na dimensão social do aluno no que diz respeito a importância afetiva e social. Com cuidados em abordar os riscos não só para a vida, mas também para a saúde da menina já que uma gravidez se não for bem tratada pode ocasionar riscos de vida. ${ }^{14}$

Em relação aos alunos que alegam motivos pessoais para serem isentos das aulas de educação física, foram encontrados 7 casos representando 7,2\% dos alunos pesquisados 2 dizem ser por motivos relacionados a violência urbana representando 2,1\%, 3 alegam que estão cuidando de algum familiar representando 3,1\%, 1 alega estar de luto e não ter condições psicológicas de frequentar as aulas, e outro não quis especificar o motivo, ambos correspondendo a $1 \%$.

Esses motivos não são representados por declarações, por isso são registrados no diário escolar do professor, onde o mesmo conversa com os alunos ou parentes do aluno e analisa se pode ou não ser caracterizado como motivo coerente para a ausência nas aulas, sem ter viés para formalizar isso através de um atestado ou documento, apenas o registro no diário formaliza essa condição de dispensa, por exemplo, pessoas que cuidam de familiares, em muitos casos irmãos menores ou parentes mais idosos, que pode até caracterizar um tipo de trabalho não remunerado ou de caráter voluntário, outros casos são de alunos que tem algum familiar envolvido com violência que apesar de ser um problema de ordem pública, acaba por atingir vários campos da sociedade como o caso de alunos de escolas públicas. 
Quando analisamos alguns desses casos, chegamos a conclusão que alguns fatores da sociedade tem ligação direta com esses motivos pessoais alegados pelos alunos, como o caso da violência urbana, segundo os dados de uma pesquisa nacional divulgados em 2013, o Ceará é considerado o $2^{\circ}$ Estado mais violento do Brasil, de acordo com a $8^{a}$ edição do Anuário do Fórum Brasileiro de Segurança Pública, ${ }^{15}$ houve um aumento de 16,5\% em relação aos homicídios no ano anterior, 2012, quando a taxa ficou em 41,5 casos por cem mil habitantes.

Em relação ao período de emissão dos atestados, dos 100 alunos pesquisados, 82 dos alunos emitiram o documento em menos de seis meses, representando $84,5 \%$ do total, 8 emitiu o documento a mais de seis meses, representado 8,2\%, 1 emitiu o documento a mais de um ano, representado 1,\% e 6 emitiu o documento a mais de dois anos, representando 6,2\%.

Em relação ao período de emissão desses atestados, os que contêm um período de mais de seis meses representam os alunos que precisaram renovar seus atestados porque já passaram do prazo de vencimento, os que representam mais de um ano, por exemplo, são os atestados que não precisam de renovação, cabe ao professor ter esse controle sobre o período de emissão dos atestados.

Analisando os resultados em relação aos atestados médicos, podemos observar o descaso com o tratamento desta questão. Segundo relatos nas conversas com professores a cerca da coleta dos atestados, alguns mencionaram sobre a importância que o aluno deve ter em se preocupar com a renovação destes atestados com no mínimo período de 6 meses após ter emitido o primeiro documento, esse prazo se dá muitas vezes por conta de muitos destes documentos não mostrarem com clareza a data de vencimento, salvo alguns casos e tipos de atestados e declarações.

No caso do aluno que terá prole, subentende-se que a mulher levará certo período de tempo para poder retornar as aulas uma vez que o tempo gasto para amamentar, cuidar nos primeiros meses, tomar cuidados como vacinação, são fatores que demandam peculiar período de tempo e que certamente fará com que este aluno demore a retornar para sala de aula. 
Nos atestados médicos geralmente o profissional da saúde especifica o período ao qual o paciente precisará ficar afastado de suas atividades estudantis, entretanto, é preciso que seja informado o novo prazo de afastamento caso ele seja ampliado, deste modo, um novo documento deve ser emitido para a escola informando sobre o novo afastamento.

Nos casos de cursos, trabalhos e estágios, a regra é a mesma, a cada semestre é importante haver uma atualização para que haja o controle, caso o aluno interrompa as atividades nesses setores é preciso que o professor de educação física seja avisado. Nos casos dos alunos que possuem problemas com acesso pela distância também se faz necessário que atualize a cada 6 meses com algum comprovante referente à residência, caso o aluno se desloque para outra localidade que o permita ter acesso à escola em outros horários, o professor também precisa ser avisado. Os casos que exigem diálogo entre aluno professor são os de pessoal e atividades extraescolares, pois é possível que esta situação seja revertida a qualquer momento.

\section{CONSIDERAÇÕES FINAIS}

Embora o foco da pesquisa tenha sido direcionado à caracterização do perfil dos estudantes que pedem afastamento das aulas de educação física escolar, bem como analisar e contextualizar esses motivos, é preciso chamar atenção para alguns outros pontos preocupantes identificados no processo da pesquisa que foram os pontos que dificultaram a realização da referida pesquisa, como fato de algumas escolas não estar tendo aulas normais de educação física escolar por problemas de ordem estrutural que passam pela organização da escola.

Alguns dos motivos constatados em grande quantidade foram de alunos que fazem cursos, estágios, trabalhos, que moram longe da escola, motivos pessoais, prática corporal extraescolar e prole, o problema subjacente se refere aos alunos precisarem realizar algumas atividades em períodos diversos das aulas decorrendo em um choque de horário da aula de educação física que se encontra ofertada no turno fora das suas demais disciplinas. Os atestados médicos e prole são motivos previstos na LDB que ocorrem de forma involuntária, é uma causalidade humana.

Os motivos relacionados a estágio, cursos e emprego apresentam maior número de pedido de afastamento, o que implica dizer que a preocupação com o mercado de trabalho é cada vez 
mais latente entre os alunos de ensino médio, isso pode ser percebido pelo fato da maioria ter incidência nas séries mais avançadas. Outro fator interessante é o das mulheres terem uma predominância na maioria dos casos, o que deixa claro que o sexo feminino possui maior preocupação em se inserir no mercado de trabalho.

O fato é que se relacionarmos as maiores incidências de motivos que geram a isenção dos alunos de acordo com os estudos, chegaremos à conclusão de que é preciso uma reformulação no currículo escolar com o intuito de tentar minimizar esses problemas, fazendo com que se entenda que o espaço da educação física deve ser respeitado assim como os demais componentes curriculares que compõem o currículo escolar.

\section{REFERÊNCIAS}

${ }^{1}$ BRASIL. Ministério da Educação e Cultura. Lei de Diretrizes e Bases da Educação Nacional. Brasília, 1996. v. 185. p. 11.

${ }^{2}$ MARTINS, Camilla. Discursos legitimadores da educação física no ensino médio. In: SEMINÁRIO DE PESQUISA EM EDUCAÇÃO DA REGIÃO SUL, 9., 2012

, Caxias do Sul. Anais... Caxias do Sul, 2012.

${ }^{3}$ LEMOS, Fabio Ricardo Mizuno. Educação física escolar, ensino médio: entre a legislação e a ação. EF Deportes: revista digital, Buenos Aires, v. 13, n. 130, mar. 2009. Disponível em: http://www.efdeportes.com/efd130/educacao-fisica-escolar-entre-a-legislacao-e-a-acao.htm. Acesso em: 25 out. 2014.

${ }^{4}$ CAVALIERE JUNIOR, Ezio; VERAS, Andreza Dantas. A Educação física escolar versus a lei de Diretrizes e Bases da Educação: LDB nº 9394/1996. EF Deportes: revista digital, Buenos Aires, v. 14, n. 134, jul. 2009. Disponível em: http://www.efdeportes.com/efd134/leide-diretrizes-e-bases-da-educacao.htm. Acesso em: 25 out. 2014.

${ }^{5}$ CARNEIRO, Elaine de Brito. Confrontos e perspectivas da educação física escolar no ensino noturno. EF Deportes: revista digital, Buenos Aires, v. 11, n. 101, out. 2006.

Disponível em: http://www.efdeportes.com/efd101/notur.htm. Acesso em: 25 out. 2014. 
${ }^{6}$ SILVÉRIO, Kátia da Silva et al. Ensino médio no período noturno: um estudo da educação física como componente curricular. EF Deportes: revista digital, Buenos Aires, v. 17, n. 174, nov. 2012. Disponível em: http://www.efdeportes.com/efd174/ensino-medio-no-periodonoturno-educacao-fisica.htm. Acesso em: 25 out. 2014.

${ }^{7}$ PIMENTEL, Alessandra. O método da análise documental: seu uso numa pesquisa historiográfica. Cadernos de Pesquisa, Londrina, n. 114, p. 179-195, nov. 2001.

${ }^{8}$ ANEXO 36: como usar o epiinfo. Disponível em:

<http://webcache.googleusercontent.com/search?q=cache:ArMcS_njY6EJ:portal.anvisa.gov. br/wps/wcm/connect/12fe49804745814d8d7add3fbc4c6735/Anexo\%2B36\%2B-

\%2BEpiInfo\%2Brevisado\%2B\%2B2.doc\%3FMOD\%3DAJPERES\%26useDefaultText\%3D0 \%26useDefaultDesc\%3D0+\&cd=5\&hl=pt-BR\&ct=clnk\&gl=br> . Acesso em: 25 out. 2014.

\section{${ }^{9}$ INSTITUTO BRASILEIRO DE GEOGRAFIA E ESTATÍSTICA (IBGE). Mulher no} mercado de trabalho: perguntas e respostas. Rio de Janeiro, 08 mar. 2012. Disponível em: http://www.ibge.gov.br/home/estatistica/indicadores/trabalhoerendimento/pme nova/Mulher M ercado Trabalho Perg Resp 2012.pdf. Acesso em: 28 set. 2014.

${ }^{10}$ ALTMANN, Helena. Rompendo fronteiras de gênero: Marias (e) homens na educação física. 1998. 119 f. Dissertação (Mestrado em Educação) - Universidade Federal de Minas Gerais, Belo Horizonte, 1998.

${ }^{11}$ BRANDÃO, Carlos da Fonseca. A situação atual do ensino médio brasileiro e as propostas para a próxima década: infraestrutura, gestão e formação do profissional que atua no ensino médio. Ensino Em Re-Vista, Uberlândia, v. 19, n. 1, p. 97-107, jan./jun. 2012.

${ }^{12}$ ROSA, Viviane Tunes da. Dispensas nas aulas de educação física no ensino médio: entre a necessidade real e o uso indiscriminado da lei. 2012. 128 f. Dissertação (Mestrado em Ciências da Educação Física) - Faculdade de Educação Física, Universidade Federal de Pelotas, Pelotas, 2012. 
${ }^{13}$ RICARDO FURTADO E ASSOCIADOS. Disponível em:

$<$ http://www.ricardofurtadoadvogados.com.br/ImprensaMostra.asp?T=M\&chave=7884 $>$.

Acesso em: 28 out. 2014.

${ }^{14}$ MÔNICO, Andréia Graziela Ferreira. Gravidez na adolescência e evasão escolar: o que a escola tem a ver com isso? Revista FACEVV, Vila Velha, n. 4, p. 39-49, jan./jun. 2010. Disponível em:< http://facevv.cnec.br/wp-content/uploads/sites/52/2015/10/GRAVIDEZNA-ADOLESC\%C3\%8ANCIA-E-EVAS\%C3\%83O-ESCOLAR-O-QUE-A-ESCOLATEM-A-VER-COM-ISSO.pdf>.

${ }^{15}$ ALVES, Pedro. Com aumento de $16 \%$ de homicídios, o Ceará é o segundo estado mais violento do Brasil. Tribuna do Ceará, Ceará, 12 nov. 2014. Disponível em:

<http://tribunadoceara.uol.com.br/noticias/segurancapublica/com-aumento-de-16-emhomicidios-ceara-e-o-segundo-estado-mais-violento-brasil/>. Acesso em: $20 \mathrm{dez} .2014$. 